\title{
Endoscopic removal of large Brunner's gland adenoma
}

\author{
${ }^{1,}$ S.J.Yaseen M.D, F.I.C.M.S, ${ }^{2,}$ F.I.C.M.S G\&H, ${ }^{3,}$ A.A.Mit'ib C.A.B.M, \\ ${ }^{4}$ H.N.Mussa \\ 1, 2, 3, 4, Hussein Teaching Hospital, Department of Gastroenterology and Hepatology, Thi-Qar, Iraq. \\ Dr.alaa jamel hasin general surgeon C.A.BS. MRCSI medical college, The-Qar University
}

\begin{abstract}
Brunner's gland adenoma (also referred to as Brunner's gland hamartoma or Brunerroma) is a rare benign tumor of the duodenum. We report a 58-year-old man presenting with recurrent upper abdominal pain of variable intensity with occasional vomiting for three years. Duodenoscopy revealed a large pedunculated polyp with along stalk arising from the posterior wall of the duodenal bulb and extending into the second part of the duodenum. Endoscopic polypectomy was performed. Histological examination revealed a Brunner's gland adenoma (hamartoma).
\end{abstract}

\section{INTRODUCTION:}

Brunner's glands were first described by the anatomist Brunner in 1688 and he thought that they are pancreas secondarium till Middeldorf (1684) correctly identified them as submucosal glands separate from duodenal glands, but structurally and functionally similar to glands of pylorus. ${ }^{(1)}$ Brunner's glands are mucussecreting acinotubular glands located in the deep mucosa and the sub mucosa of the duodenum, emptying into the crypts of Lieberkuhn. ${ }^{(2)} \mathrm{A}$ primary function of these glands is to secret alkaline mucus into the intestinal lumen in addition to other activities such as the secretion of insulin like growth factor and the lysozyme muramidase. There is also a possibility that these glands assist the function of intestinal crypts in transporting immunoglobulins into the gut lumen. In addition, they may contribute to the innate immunity in the intestinal tract. $^{(3)}$

The first to report a Brunner's gland adenoma was Cruveilhier in 1835, describing a Brunner's adenoma causing intussusceptions with patient's death. ${ }^{(1,4)}$

We present a 58-year-old man with dyspeptic symptoms for three years. Endoscopy revealed a large pedunculated polyp in the duodenum, which was endoscopically resected and proven to be a Brunner's gland adenoma on histology. The literature on Brunner's gland adenoma (hamartoma) was reviewed.

\section{Case Report:}

A 58-year-old man has upper abdominal pain and occasional bouts of vomiting for three years. He used to use over the counter medications and self prescriptions for his symptoms then he made medical consultation when his symptoms had intensified for the last one month. He reported no weight loss and his medical history is unremarkable apart from hypertension for five years controlled by tenormen $100 \mathrm{mg}$ single dose daily. Physical examination revealed no abnormality. Complete blood count, blood sugar, liver enzymes and blood urea nitrogen all came normal. Abdominal ultrasound examination done to him and was reported as normal too. OGD disclosed a large duodenal polyp with smooth surface and a long stalk arising from the duodenal bulb and extending into the second part. A duodenoscope then used and a polypectomy was performed using coagulation current. The polyp was $3 \times 2 \times 1 \mathrm{~cm}$ in size with lobulated surface. Histopathology reported a Brunner's gland adenoma (hamartoma). Follow up endoscopy six months and two years later show no recurrence of the lesion and the patient was free of symptoms.

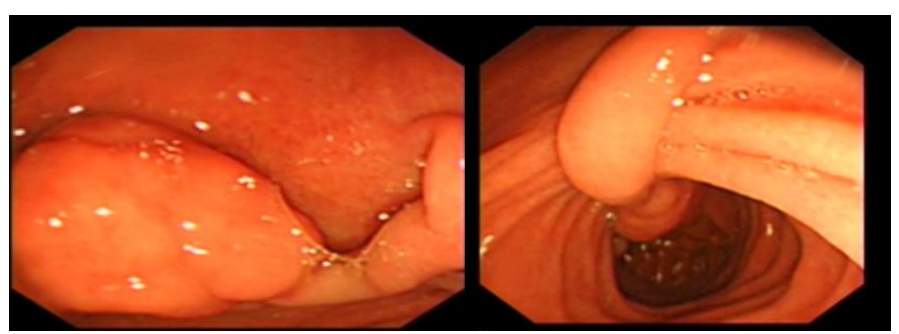

Fig. 1 and 2. Endoscopic view of big pedunculated Brunneroma arising from the duodenal bulb and falling into the second part. 


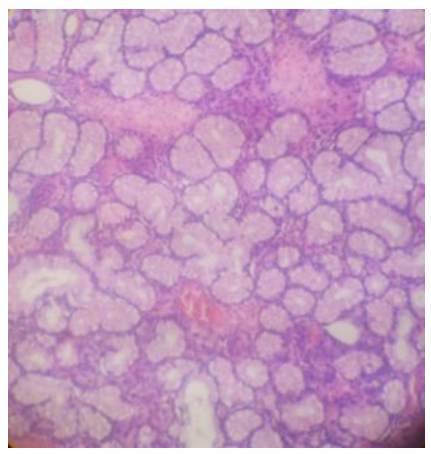

Fig. 3. Photomicrograph of Brunner's gland hyperplasia shows proliferation of Brunner's glands. (H and E, $\times 10)$

\section{DISCUSSION:}

Benign tumors of the duodenum are rare. They are reported in $0.008 \%$ of the patients at autopsy; Brunner gland adenoma comprises $10.6 \%$ of these lesions. ${ }^{(4,5)}$

Brunner's glands are mucin-secreting glands situated in the deep mucosa and the submucosa of the duodenum.

(6) They extend from the pylorus distally to a variable distance usually up to the D2 segment, although in rare occasions it may reach up to the proximal jejunum, even the distal ileum, but they are most numerous in the proximal part of the duodenum immediately distal to the pylorus and diminished in size and number as they go distally. In infants they occupy $55 \%$ of the total duodenal area; by 50 years of age this drops to $35 \%$. $^{\text {(7) }}$ Brunner's gland adenomas have been reported in the proximal jejunum and in the proximal ileum. ${ }^{(4)}$

\section{REFERENCES:}

1. Chattopadhyay P, Kundu A K, Bhattacharyya S, et al.Diffuse nodular hyperplasia of Brunner's gland presenting as upper gastrointestinal haemorrhage. Singapore Med J 2008; 49 (1) : 81

2. Janes SEJ, Zaitoun AM1, Catton JA, et al. Brunner's gland hyperplasia at the ampulla of Vater.J Postgrad Med March 2006 Vol 52 Issue 1.

3. Helio B. coutinho', Tania I. robalinho', Vera B. coutinho', et al. Immunocytochemical demonstration that human duodenal Brunner's glands may participate in intestinal defence. J. Anat. (1996) 189, pp. 193-197.

4. J.M. Jansen, W.N.H.M. Stuifbergen, A.W.M. van Milligen de Wit. Endoscopic resection of a large Brunner's gland adenoma. The Netherlands journal of medicine. JULY 2002, VOL. 60, NO. 6253.

5. Kovacevic I, Ljubicic N, Cupic H, et al. Helicobacter pylori infection in patients with Brunner's gland adenoma. Acta Med Croatica 2001; 55:157-60.

6. Henken EM, Forouhar F. Hamartoma of Brunner's gland causing partial obstruction of the ileum. J Can Assoc Radiol 1983; 34:73-4.

7. Fuller JW, Maj MC Cruse CW, Williams JW. Hyperplasia of Brunner's glands of the duodenum. Am Surg 1997; 43:246-50. 